\title{
ADHESION STRENGTH OF TEMPERATURE VARIED NANOCELLULOSE ENHANCED WATER BASED PAPER AND CARDBOARD ADHESIVES
}

\author{
Barbara Šumiga $^{1}$ (D) , gor Karlovits $^{1}$ (D), Boštjan Šumiga ${ }^{2}$ \\ ${ }^{1}$ Pulp and Paper Institute, Ljubljana, Slovenia \\ ${ }^{2}$ University of Ljubljana, Faculty of Natural Sciences and Engineering, Ljubljana, Slovenia
}

\begin{abstract}
Water-based dispersion adhesives consist of a solid adhesive dispersed in an aqueous phase. These adhesives contain water-soluble additives such as surfactants, emulsifiers, and protective colloids, which act as links between the solid adhesive particles and the aqueous phase. They prevent the adhesive particles from sticking together and separating during storage. During drying, these additives evaporate or are absorbed into the adhesive. Polyvinyl acetate (PVAC) and polyvinyl alcohol (PVOH) are further examples of ethylene copolymers. PVAc is used as an emulsion adhesive for production of bags, sacks and cartons. Recently there have been some preliminary investigations concerning the addition of nanocellulose as adhesion improver. Nanocellulose is a term that refers to nanostructured cellulose. It can be either cellulose nanocrystal (CNC or NCC), cellulose nanofibres (CNF) also called nanofibrillated cellulose (NFC), or bacterial nanocellulose, which refers to nanostructured cellulose produced by bacteria. CNF is a material consisting of nanofibrillated cellulose fibrils with a high aspect ratio (length to width ratio). In this study, we tested the adhesion strength of two PVAC adhesives by adding 0,5, 1 and 2\% [wt.\%] of two types of nanocellulose to two commercial adhesives. The adhesive was applied to the cardboard with a rod coater. To test the influence of temperature, we varied the mixture at two different temperatures $\left(23\right.$ and $\left.45^{\circ} \mathrm{C}\right)$. The adhered samples were tested for $z$-direction tensile strength (according to ISO 15754:2009) and T-peel test (ASTM D1876-08) on a mechanical testing device. The results showed no significant improvement in adhesion strength compared to pure adhesive, indicating that further optimization of the adhesive mixture and testing procedure is required.
\end{abstract}

Keywords: adhesion strength, nanocellulose, paper, PVAc

\section{INTRODUCTION}

Adhesives are used in a wide range of paper bonding applications, from the construction of corrugated boxes and lamination of printed sheets to packaging materials for all types of consumer goods to the manufacture of large industrial tubes and cores used by producers of rolling stock and other materials. Adhesives are used to bond cardboard surfaces together and create a permanent bond. The bond formed by adhesion must be strong enough to be processed as soon as the paperboard leaves the glueing machine. Therefore, the adhesive must be selected by taking into account the absorption properties such as setting time which is adapted to the paperboard and the glueing line process. The main criterion for successful glueing of packaging products is almost always a $100 \%$ fibre tear when the adhesion line is separated. The type of adhesive typically used to bond coated paperboard substrates is based on polyvinyl acetate (PVAc) chemistry together with water and other additives for functionality. In order to achieve uniform fibre tearing when bonding coated/uncoated substrates, the base sheet of both substrates must always be the weakest link when separating. The mechanism for achieving a uniform fibre tear under the coated surface is such that adhesive carriers (mainly water) must penetrate the fibre matrix to cause "fibre bond breaks" (weakening) which in turn trigger a fibre tear. During this process, adhesive particles are trapped in the pores of the substrate where they "harden" and form a permanent bond (Parker, 2004). The importance of porosity for the penetration of water-based PVAc adhesive has been investigated and confirmed by microscopic measurements (Williams et al., 2011). In a study by (Petković et al., 2016) they tested various other paper properties and polyvinyl acetate adhesives. Their research indicates that the influence of the ratio between polar and disperse fractions on the decreasing or increasing influence of the free energy between the phases has an impact on the adhesive joint. The interphase energy controls the durability and strength of an adhesive joint and is primarily responsible for the transfer of stress from one adhesive to another. The analysis of fillers showed that the increased amount due to ion-dipole interactions could reduce the interphase energy between these two phases.

On the other hand, in addition to stickiness and adhesiveness of cardboard and paper, the adhesive formulations are also essential. Polyvinyl acetate (PVAc) and polyvinyl alcohol (PVOH) are further examples of ethylene copolymers. PVAc is used as an emulsion adhesive for the production of bags, sacks 
and cardboard boxes. PVOH is produced by hydrolysis of PVA, and the strong hydrogen bonding mediated by the $-\mathrm{OH}$ groups means that pure $\mathrm{PVOH}$ is water-soluble. The amount of hydrolysis controls the degree of water solubility. PVAc softens when its temperature is raised above room temperature and is less resistant to moisture and humidity than thermosetting resins.

For this reason, PVAc adhesives are used in indoor applications. Besides, PVAc tends to creep ('cold flow') under prolonged exposure (Conner and Bhuiyan, 2017). Previous research on some adhesives of plywood to paper has shown the positive effect of adding nanocellulose on adhesion strength and has enabled a remarkable increase in shear strength values to be achieved. The introduction of cellulose nanoparticles has had a positive influence on mechanical properties such as flexural bending strength and modulus of elasticity. Advantages of using nanocellulose as reinforcement in adhesives for the production of woodbased panels are the possibility to modify the properties of the adhesives, the improvement of the mechanical and physical properties of the panels and the reduction of formaldehyde emissions through the use of synthetic adhesives. A variation in viscosity was observed with an increasing percentage of cellulose nanocrystals (CNC) added to the adhesive (Damásio et al., 2017), while in (Vineth et al., 2019) an overview of nanocellulose applications in wood adhesives was given. In a study on PVAc adhesives (Jiang et al., 2018), the results showed that the optimal amount of CNF, $0.48 \%$ suspensions, added to PVAC increased the average overlap joint strength (EN 205:2003) by 74.5\% compared to control samples with pure PVAc. Accordingly, $0.96 \%$ of CNF suspensions also increased the strength of the starch adhesive by 34.5\%. Lower and higher CNF concentrations showed a significantly worse performance.

Further studies were conducted by (Veigel et al., 2011). Temperature changes of PVA adhesives on wood panels were studied by (Motohasi et al., 1984). They concluded that the adhesive strength is strongly dominated by the final strength of the adhesive films, which in turn depends on rheological fluctuations caused by temperature changes, i.e. if adhesive polymers are in a rubbery state corresponding to a high test-temperature, the adhesive strength is weak due to cohesive fracture of the adhesives. As adhesive polymers harden with decreasing test-temperature, the bond strength increases to a maximum where the wood/adhesive interface force appears to be most effective. If the test-temperature is lowered from this point, the strength begins to decrease significantly due to the decreasing interfacial forces in the case of the cross-impact lap test. In a review by Heinrich (2019) some problems with nanocellulose as an additive in adhesives has been pointed out. The water content of nanocellulose, which is generally up to $97 \%$, and its price. A solution to the first problem seems to be cold pressing the water after slurry, while a solution to the second problem could be the use of lignocellulose nanofibers obtained from recycled particleboards or other sources. If these developments are successful, the nanocellulose could have a function both as structural reinforcement and as an adhesive material in the product. Since the addition of nanocellulose as an additive in PVAc adhesives for paper and board (mainly for wood panels) is not being extensively investigated, we have tested two PVAc adhesives with two different types of nanocellulose.

\section{MATERIALS AND METHODS}

To test the adhesion strength of the nanocellulose reinforced PVAc adhesives we used a commercial 235 $\mathrm{g} / \mathrm{m}^{2}$ cardboard (produced by Količevo Karton) with $5 \%$ surface treatment and total absorption (DIN ENISO 535) of the $60 \mathrm{~s}$ under $30 \mathrm{~g} / \mathrm{m}^{2}$ from COBB. As adhesives, we used two types of PVAc adhesives MEKOL 1301/1 (M1) and MEKOL 1413/G (M2) (produced by Mitol d.d., Slovenia). The adhesive MEKOL $1301 / 1$ has $50 \%$ solids content (ISO 3251) and initial viscosity at room temperature $\left(23^{\circ} \mathrm{C}\right)$ of $1.700-$ $2.200 \mathrm{mPa}$ s (ISO 2555 - Brookefiled) while the adhesive MEKOL 1413/G has 46,5\% solids content and viscosity at room temperature of $15.000-22.000 \mathrm{mPa}$ s (ISO 2555 - Brookefield). For both adhesives, an excellent working adhesion range up to $250^{\circ} \mathrm{C}$ was specified. The main difference is that adhesive MEKOL $1413 / \mathrm{G}$ forms a more elastic film after drying. For the nanocellulose, we used two different types of it: nanocrystalline (NCC) with a solid content of 7,8 \% and a diameter of 10-20 nm and a length of 40-200 $\mathrm{nm}$ (produced by National Institute of Chemistry, Ljubljana, Slovenia) and commercial nanofibrillated cellulose (NFC) with a solid content of $4 \%$ and a diameter of 10-200 nm and a length of $<50 \mu \mathrm{m}$. The nanocellulose was added in the ratio of 0,5, 1 and $2 \%$ content (weight \%). All determined quantities of nanocellulose were weighed and added to the adhesive. The adhesive formulations were prepared using IKA digital overhead stirrer. Homogenization was achieved by intensive mixing of the prepared mixtures for at least 3 minutes at a mixing speed of $2000 \mathrm{rpm}$. For the application of the adhesive, a laboratoryscale rod coater (K Control Coater, RK PrintCoat Instruments Ltd., Litlington, UK) was used. We have applied the rod with the number 4 and the speed 6. Immediately after the adhesive coating, a new sheet 
was glued onto the adhesive layer. Then we used rod number 0 to achieve the same pressure over the entire paper surface. In the second series of adhesive applications performed, the applied elevated temperature was $45^{\circ} \mathrm{C}$. The amount of adhesive which was applied was minimal in order to minimize the possible tearing of the cardboard layers, to isolate and determine the adhesive strength of the different adhesive formulations and to exclude the adhesive strength of the cardboard. The determination of the adhesive strength between the two adhered cardboard sheets was carried out with mechanical testing device ZWICK/Roell Z010 using the analytical methods Z direction tensile strength (ISO 15754:2009) and T- peel test (ASTM D1876-08).

\section{RESULTS}

The results for the z-direction tensile strength for the different amounts of NCC and NFC (for both temperatures) are shown in Figure 1.

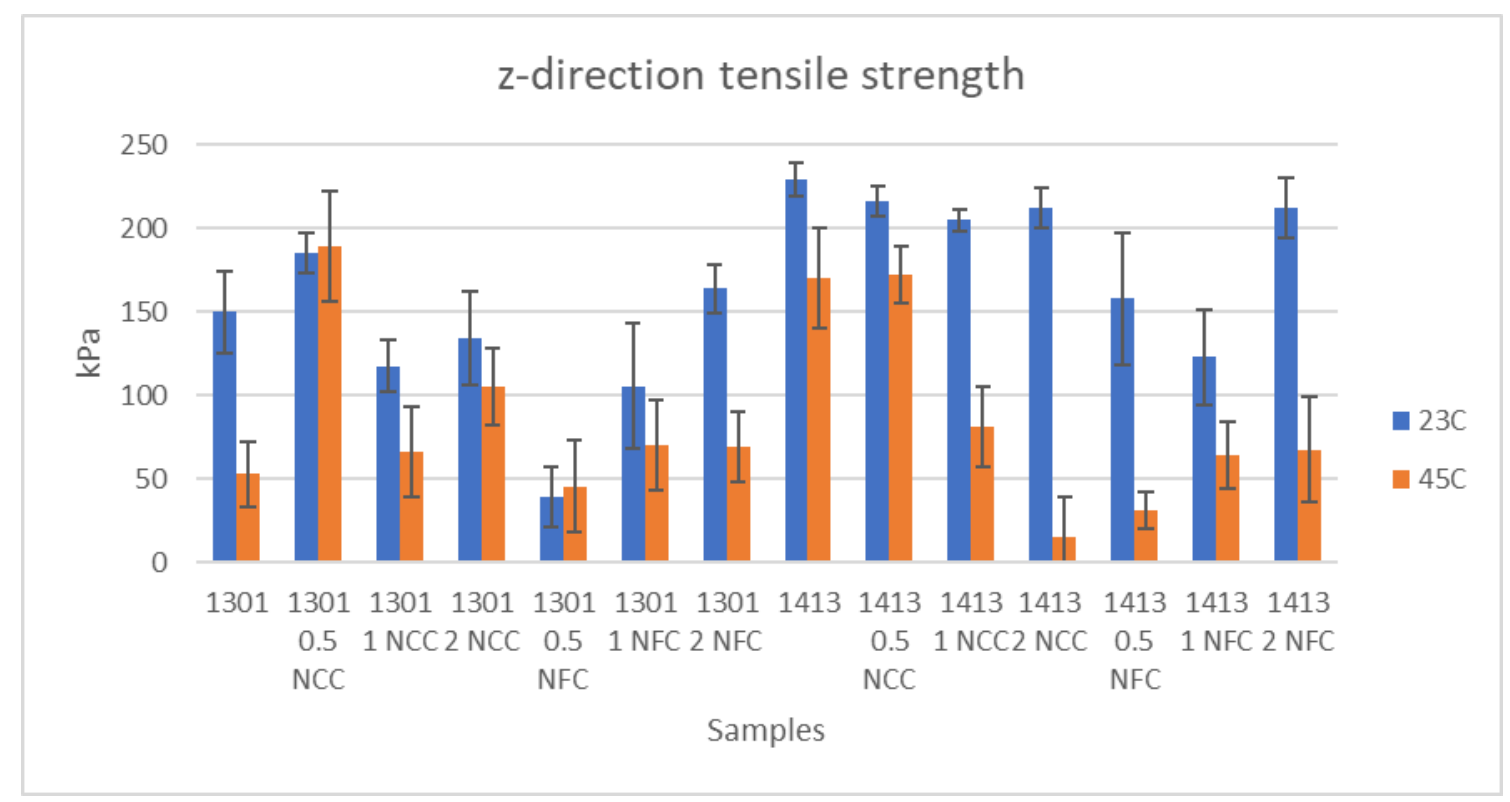

Figure 1: Z- direction tensile strength

From the tensile strength results in the z-direction, it can be seen that at room temperature (and in the optimum temperature range concerning the base adhesive) the addition of NCC and NFC has improved the tensile strength of the samples in the z-direction compared to the $\mathrm{M} 1$ adhesive alone. For the adhesive $\mathrm{M} 2$, the addition resulted in similar or slightly lower tensile strength. The temperature increase of the adhesive mixtures resulted in lower $\mathrm{kPa}$ values in almost all samples except the mixtures with the lowest concentration (0,5 \% wt). The increased temperature and lower water content resulted in lower $\mathrm{z}$ tensile strength values for both NCC and NFC compounds. From Figure 2., it is clear that the most common joint failure and adhesion separation was due to delamination of the cardboard ply's rather than the adhesive joint. This effect means that the cardboard internal cohesion values are lower than the adhesive strength. On the right side of the Figure 2. which was taken on samples with elevated temperature of the applied adhesive, it can be seen that the cohesion failure, was between two cardboard samples where the adhesive was applied. 

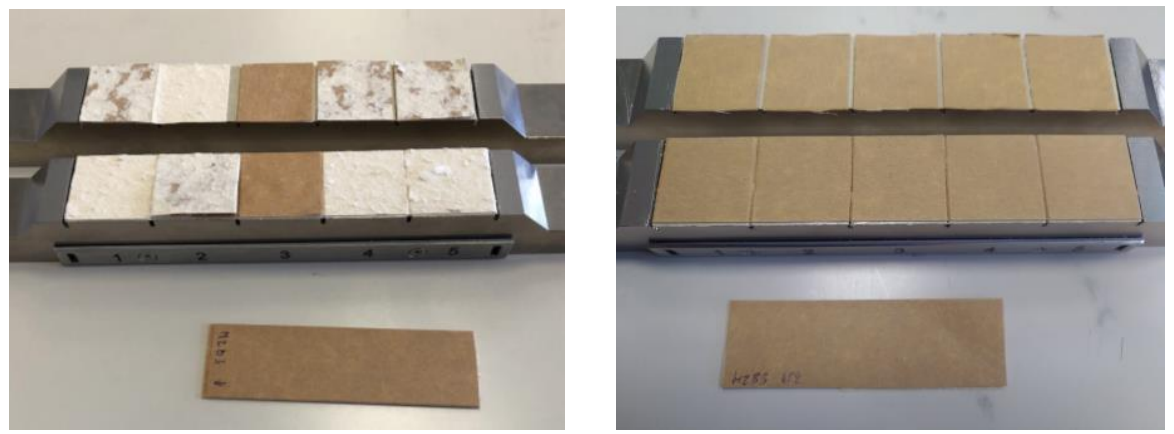

Figure 2: Z- direction tensile strength samples after the test has been performed

The results for the T-peel test for the samples joined at room temperature $\left(23^{\circ} \mathrm{C}\right)$, and elevated temperature is shown in Figure 3.

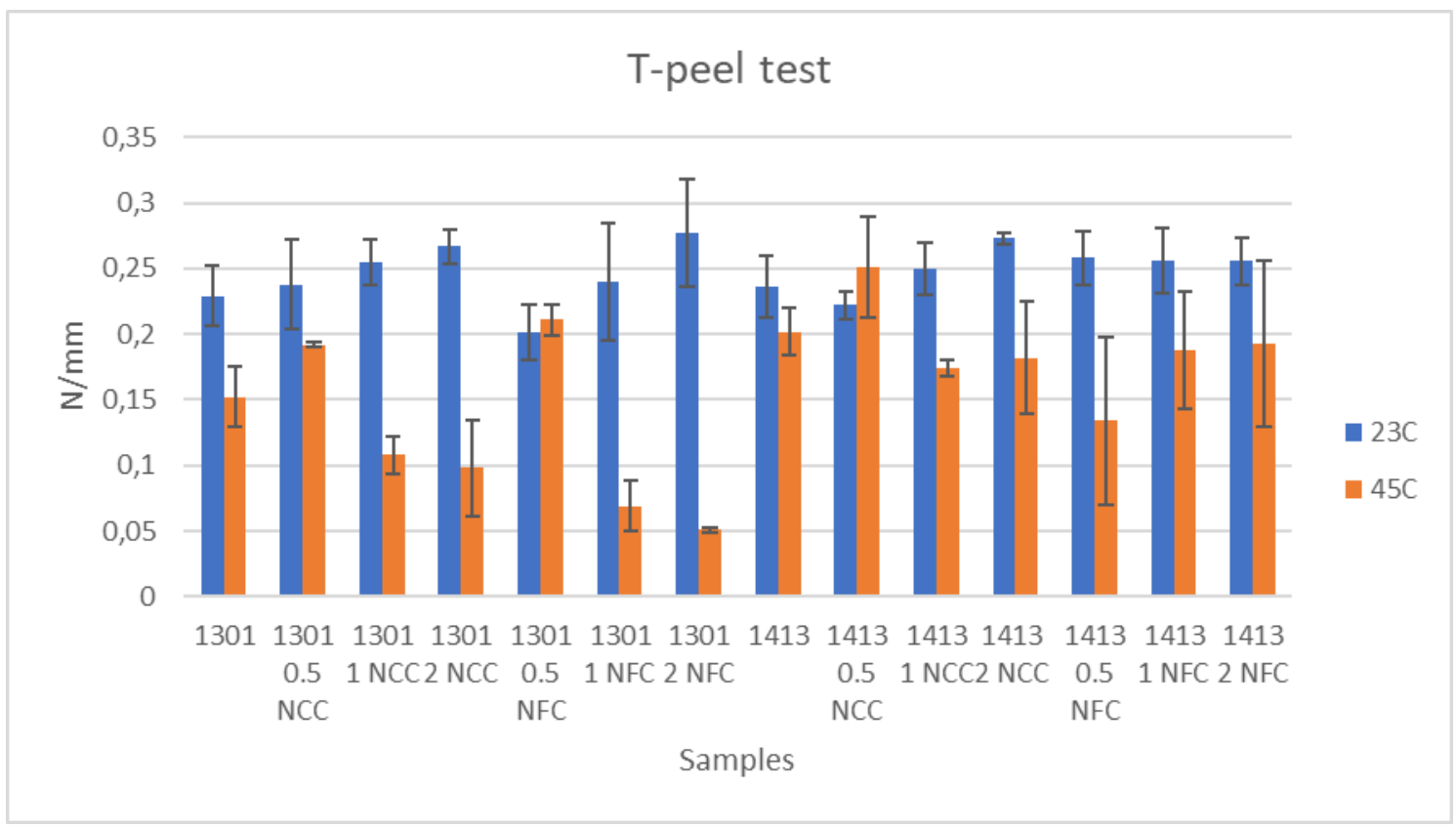

Figure 3: T peel adhesion strength

From Figure 3, we can observe that the addition of NCC and NFC positively influences the average N/mm values for all combinations $(0,5 \%, 1 \%$ and $2 \%)$ and in all cases, the peel adhesion strength was higher (except M1 NFC 0,5\%) and M2 (0,5\% NCC) which may indicate that higher concentrations of NCC and NFC at room temperature lead to higher peel strength values. Also, it can be seen that the increased temperature lowered the adhesion strength values for all adhesives and adhesive formulation combinations, but the NCC and NFC additives had even higher values for the M1 base adhesive and similar values for the $\mathrm{M} 2$ adhesive.

\section{CONCLUSION}

Replacing synthetic components in adhesives with natural ones is a challenge from various aspects regarding chemical compatibility, pricing and application technology. The addition of NCC and NFC in adhesives has proved useful in wood composites, while our results show mixed results, with the addition of NFC and NCC in some cases giving higher and slightly lower values in the z-direction tensile strength measurements. In the $\mathrm{T}$ peel adhesion test at room temperature, the addition was beneficial for both additives as the average peel force $(\mathrm{N} / \mathrm{mm})$ increased. One of the possible reasons for differences between the two test methods could also be the variation in the adhesive application, where the rod system creates a slight time delay between the sample sides, with the bottom side having more moisture 
at the moment of contact of two cardboard layers. Due to this effect, the z- strength method can lead to a higher variation of results. The increased temperature caused a deterioration of the basic components, and the results were not as consistent. The ambiguous results indicate that in our future research we need to optimize the mixtures, procedures further, and compatibilities of the NCC and NFC addition with the base adhesive formulations and investigate the influence of the water content on the adhesive strengths of the paper and board compound.

\section{ACKNOWLEDGMENTS}

We want to thank company Mitol, d.d. for providing the base adhesive samples.

\section{REFERENCES}

[1] Conner A.H., Bhuyian M.S.H.: "Wood: Adhesives", In book: Reference Module in Materials Science and Materials Engineering, Elsevier, 2017. doi: 10.1016/B978-0-12-803581-8.01932-9.

[2] Damásio, R., Carvalho, A., Gomes, F., Carneiro, A., Ferreira, J., Colodette, J.: "Interação de nanocristais de celulose com o adesivo ureia-formaldeído em juntas coladas de Eucalyptus sp. ", Scientia Forestalis 45(113), 2017. doi: 10.18671/scifor.v45n113.17.

[3] Heinrich, L.A.: "Future opportunities for bio-based adhesives - advantages beyond renewability", Green Chemistry 21(8), 1866-1888, 2019. doi: 10.1039/c8gc03746a.

[4] Jiang, W., Tomppo, L., Pakarinen, T., Sirviö, J., Liimatainen, H., Haapala, A.: "Effect of Cellulose Nanofibrils on the Bond Strength of Polyvinyl Acetate and Starch Adhesives for Wood", BioResources 13(2), 2018. doi: 10.15376/biores.13.2.2283-2292.

[5] Parker, Q.: "Aqueous Gluing of Coated Paperboard Packaging Products in North America, Solutions! Online Exclusives, April 2004", URL: https://imisrise.tappi.org/TAPPI/Products/04/APR/04APROE01.aspx (last request: 2020-09-15).

[6] Petković G., Rožić M., Vukoje M., Pasanec P.: "Interactions in polyvinyl acetate - paper adhesive joint and influence on its adhesion parameters", Proceedings of 8th International Symposium on Graphic Engineering and Design 2016, (University of Novi Sad, Serbia, 2016), pages 91-101.

[7] Veigel, S., Müller, U., Keckes, J., Obersriebnig, M., Gindl-Altmutter, W.: "Cellulose nanofibrils as filler for adhesives: effect on specific fracture energy of solid wood-adhesive bonds", Cellulose 18(5), 1227-1237, 2011. doi: 10.1007/s10570-011-9576-1.

[8] Vineeth, S., Gadhave, R., Gadekar, P.: "Nanocellulose Applications in Wood Adhesives-Review", Open Journal of Polymer Chemistry 09(04), 63-75, 2019. doi: 10.4236/ojpchem.2019.94006.

[9] Williams, D., Ninness, B., Ventresca, D., Welsch, G.W.: "Microscopy Characterization of Aqueous PVAc Glue Penetration in Double Coated Paperboard Systems", Microscopy and Microanalysis 17(S2), 1046-1047, 2011. doi: 10.1017/S1431927611006106.

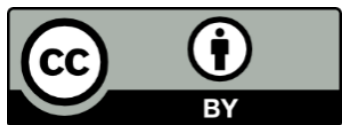

(C) 2020 Authors. Published by the University of Novi Sad, Faculty of Technical Sciences, Department of Graphic Engineering and Design. This article is an open access article distributed under the terms and conditions of the Creative Commons Attribution license 3.0 Serbia (http://creativecommons.org/licenses/by/3.0/rs/). 